\title{
A Simple and Dependable Technique for Pancreatic-Enteric Anastomosis with a Soft Pancreas and Nondilated Duct
}

\author{
Daniel Vasilev Kostov ${ }^{1}$, Georgi Leonidov Kobakov², Daniel Veselov Yankov, \\ Kiril Georgiev Kirov ${ }^{2}$ \\ ${ }^{1}$ Department of Surgery, Naval Hospital of Varna, Varna, Bulgaria \\ ${ }^{2}$ Clinic of Surgery, Specialized Hospital for Oncologic Diseases of Varna, Varna, Bulgaria \\ Email: ${ }^{*}$ danielkostov@abv.bg
}

Received 19 August 2014; revised 16 September 2014; accepted 10 October 2014

Copyright @ 2014 by authors and Scientific Research Publishing Inc.

This work is licensed under the Creative Commons Attribution International License (CC BY). http://creativecommons.org/licenses/by/4.0/

\section{Open Access}

\begin{abstract}
Background: Pancreatic anastomotic leakage is one of the most serious complications following pancreaticoduodenectomy (PD). The most significant risk factors for pancreatic leakage are pancreatic texture, main pancreatic duct (MPD) size and anastomotic technique. Herewith we describe our technical modifications for single-layer pancreaticojejunostomy (PJ) with a soft pancreas and nondilated MPD for reconstruction after PD. Methods: We report our early experience using this technique in 52 patients who underwent PD between May 2009 and December 2012. Results: Overall postoperative mortality rate was $1.92 \%$. Postoperative morbidity rate was $32.69 \%$, with major complications occurring in three patients $(5.77 \%)$. Pancreatic leak was diagnosed in six patients (11.54\%). Three patients with pancreatic fistulae (PF) of Grades A and B were managed conservatively, whereas three other patients with $\mathrm{PF}$ of Grade $\mathrm{C}$ required relaparotomy. Conclusions: According to our early experience with this modified technique for PJ, usage of horizontal mattress sutures, "everting" of MPD and incorporation of its wall into a single layer pancreatic-enteric anastomosis result in a low pancreatic anastomotic leakage rate after PD. This technique for PJ with a soft pancreas and nondilated duct ensures ideal preconditions for anastomosis healing. They consist of an excellent blood supply, an anatomical position with tension-free approximation and unobstructed pancreatic juice flow from the pancreas into the jejunal loop.
\end{abstract}

\section{Keywords}

Pancreaticoduodenectomy, Single Layer Pancreaticojejunostomy, Soft Pancreas, Nondilated Duct, Pancreatic Anastomotic Leak

\footnotetext{
${ }^{*}$ Corresponding author.
}

How to cite this paper: Kostov, D.V., Kobakov, G.L., Yankov, D.V. and Kirov, K.G. (2014) A Simple and Dependable Technique for Pancreatic-Enteric Anastomosis with a Soft Pancreas and Nondilated Duct. Surgical Science, 5, 444-453. 


\section{Introduction}

Pancreaticoduodenectomy (PD) remains the procedure of choice for treatment of periampullary and pancreatic head cancer. Mortality rate after pancreatic surgery has decreased over the past decade, especially in high-volume centres, and is currently below 5\% [1] [2]. In spite of advances of surgical techniques and perioperative management, morbidity rate remains high and about 18\% - 54\% [1] [3]. The pancreatic anastomosis leak with development of a pancreatic fistula (PF) and associated complications is the most feared cause of morbidity [4]. This represents the most serious complication, accounting for up to $80 \%$ of postoperative deaths [5].

Many concepts have been discussed and numerous variations in the management of the pancreatic stump have been described, ranging from ligation or sealing of the main pancreatic duct (MPD) to pancreaticojejunostomy (PJ) using various methods and, more recently, pancreaticogastrostomy [6]. The best pancreatic anastomosis technique after PD is still debated [7]. PJ is the preferred method for anastomosis, however, PF incidence does not seem different according to the many techniques proposed for pancreatic digestive continuity reconstruction [8]. Moreover, pancreatic anastomotic leakage occurs more likely in a patient with a soft pancreas and nondilated pancreatic duct than in a patient with a hard pancreas and a dilated duct [9]. Cho et al. carried out a simple and safe dunking PJ using mattress sutures in pure laparoscopic PD in 15 consecutive patients with a soft pancreas and a nondilated pancreatic duct and established grade A PF in only three of them [10]. A less demanding PJ technique has been developed that creates an end-to-end intussuscepting PJ using a running monofilament suture after PD [11]. A new type of transductal invaginational pancreatico-jejunostomy (TDI) was applied in 29 patients to successfully prevent pancreatic leakage after PD [12]. Kakinoki et al. apply a triple secured technique with ultrasonic dissector for pancreatic transection with skeletonizing and ligating the small pancreatic branch ducts, duct-invagination or duct-to-mucosa anastomosis for MPD management and four large stitches between the pancreatic stump parenchyma and the jejunal seromuscular layer to prevent minor pancreatic leakage in 28 consecutive patients with soft pancreas after PD [13].

Comparisons of different techniques and variations in terms of safety, feasibility, and short- and long-term outcomes do not provide any consensus among surgeons as to which technique offers the best outcome [6].

Herewith we report our own early experience with a particular single-layer PJ technique with a soft pancreas and nondilated duct and evaluate the results of postoperative complications.

\section{Methods}

\subsection{Terminology}

PFs were identified by the presence of amylase-rich fluid of more than three times than the serum concentration collected from postoperative day 3 from the drain placed intraoperatively in the abdomen, in accordance with criteria defined by the International Study Group on Pancreatic Fistula (ISGPF) [14]. Haemorrhage was defined according to ISGPF criteria by three parameters, including onset, location and severity [15] and classified as Grade A, B or C. Sepsis was defined by the presence of both infection and systemic inflammatory response. Septic shock was defined as severe sepsis complicated by organ dysfunction plus a status of acute circulatory failure characterized by persistent arterial hypotension despite adequate fluid resuscitation [16]. Delayed gastric emptying (DGE) was defined as the inability to return to a standard diet by the end of the first postoperative week and included prolonged patient's nasogastric intubation according to ISGPS definition [17] [18]. Pancreas texture was then assessed and classified as soft or hard, as suggested by Reid-Lombardo et al. [19].

\subsection{Eligibility Criteria}

Inclusion criteria were the following: 1) a soft pancreas, 2) nondilated MPD (diameter $\leq 2 \mathrm{~mm}$ ), and 3) malignant disease of the pancreatic head and of the periampullary region.

\subsection{Patients}

We prospectively reviewed 52 consecutive patients (24 women and 28 men; mean age 62.3 years) who underwent PD (either pylorus-preserving or classical Whipple's) carried out using our technique for PJ, during a three-year period (between May 2009 and December, 2012). Indication for PD was pancreatic duct carcinoma in 46 patients (88.46\%) and ampullary carcinoma in six ones (11.54\%). All the procedures were performed by the 
same surgeon using the same technique, same approach and same anastomotic fashion in order to avoid technical bias. All the patients underwent preoperative contrast-enhanced computed tomography (CT) to assess operability. In selected cases, magnetic resonance imaging (MRI) and endoscopic ultrasound were also used to help defining the operability. Although it is not our policy to perform routine preoperative biliary drainage, it has already been carried out in the majority of patients prior to referral to our unit. Drain amylase was checked in any cases on postoperative day three and, if the drain amylase was not elevated, the drain was removed on day five.

\subsection{Surgical Technique}

The patient is cleaned, draped and catheterized with a central venous and an intraarterial line. A bilateral subcostal incision is made. The abdomen is explored for metastases. Standard PD is performed if the tumour is deemed resectable after exploration. The pancreatic remnant is mobilized for $1 \mathrm{~cm}$ from the retroperitoneum and ascertained for texture and MPD size. The ductal wall is liberated from pancreatic tissue at $2-3 \mathrm{~mm}$ caudally to the cut end (Figure 1). A single jejunal loop is used for both PJ and biliary anastomosis. This loop is usually brought up in the retrocolic manner. $\mathrm{PJ}$ is a single-layer end-to-side anastomosis.

\subsubsection{Step One: Posterior Ductal Sutures}

The first step involves placement of at least three interrupted sutures on the posterior ductal wall, taking care to avoid any MPD inclusion in the suture by using a metal probe or stent within the duct. It is noteworthy that polydiaxone sutures (PDS) 5 - 0 must traverse the full thickness of the pancreatic parenchyma from the dorsal pancreatic surface until the needle comes out from the posterior ductal wall, 2 - $3 \mathrm{~mm}$ caudally to the cut end (Figure 2).

\subsubsection{Step Two: Anterior Ductal Sutures}

The second step consists in a similar placement of sutures on the anterior ductal wall. Here again one must ensure that the interrupted sutures traverse the full thickness of the pancreatic parenchyma from the anterior wall

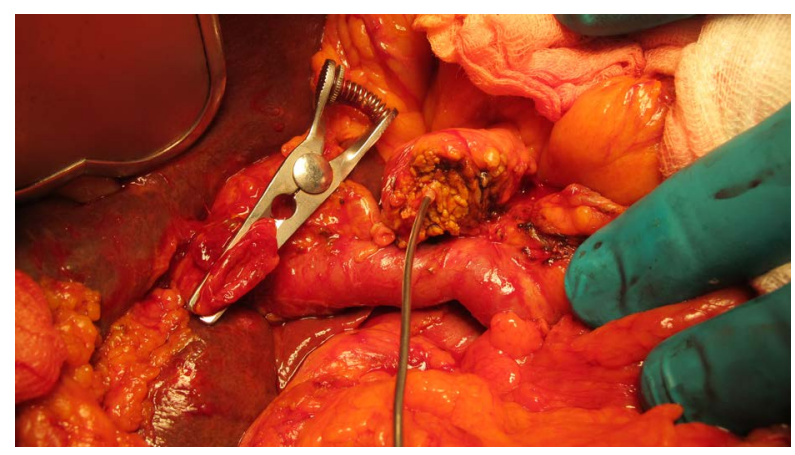

Figure 1. Pancreatic remnant is assessed for texture (soft pancreas) and MPD size (diameter $<3 \mathrm{~mm}$ ).

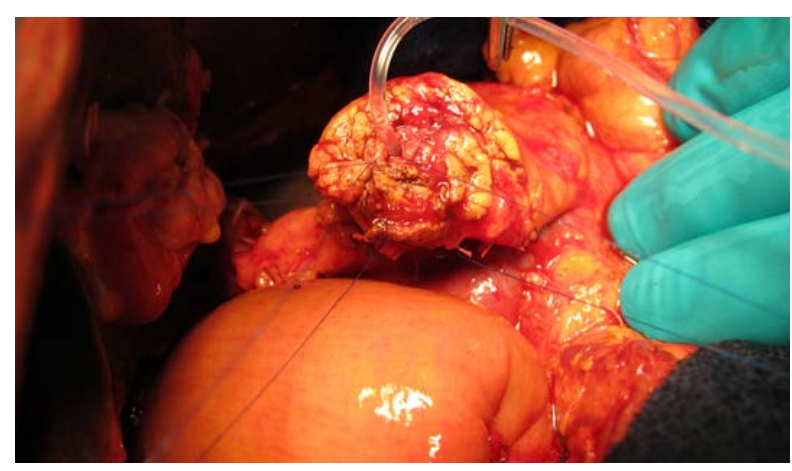

Figure 2. Posterior ductal sutures. 
of the duct until the needle comes out from the anterior pancreatic surface. The sutures pass through the ductal wall, 2 - $3 \mathrm{~mm}$ caudally to the cut end. The total number of ductal sutures required varies from four (3, 6, 9 and 12 o'clock) to five (Figure 3).

\subsubsection{Step Three: Posterior Layer}

The posterior layer is a series of three to four horizontal mattress sutures using PDS 4/0 between the whole pancreatic remnant to the seromuscular layer of the jejunum (Figure 4).

\subsubsection{Step Four: Opening the Jejunum}

The jejunum is opened opposite the MPD for a similar diameter. The posterior ductal sutures are also used to ensure that the posterior wall of the pancreatic duct is now anastomosed to that of the opened jejunum (Figure 5). An internal stent is then placed from the MPD to the lumen of the jejunum. Similarly to the posterior ductal sutures, the anterior ones are also used to ensure that the anterior wall of the pancreatic duct is now anteriorly anastomosed to the opened jejunum (Figure 6). The posterior and anterior ductal sutures are tied. Then the posterior horizontal mattress sutures are tied very gently to ensure adaptation of the jejunum to the posterior pancreatic capsule.

\subsubsection{Step Five: Anterior Layer}

Anteriorly interrupted sutures apposing the seromuscular layer of the jejunum to the pancreas are performed, using 4/0 PDS sutures, thus completing the PJ (Figure 7). Once PJ is completed, the same loop is used to reconstruct the bilio-enteric anastomosis. Hepatico-jejunostomy (end-to-side) at $20-25 \mathrm{~cm}$ from the pancreatic anastomosis os then performed using interrupted 5/0 PDS sutures. Bowel continuity is completed either with gastrojejunostomy or duodenojejunostomy anastomosis. A nasogastric tube is placed in the stomach for gastric decompression. Two abdominal drains are placed: one in Morrison's pouch and the other near PJ.

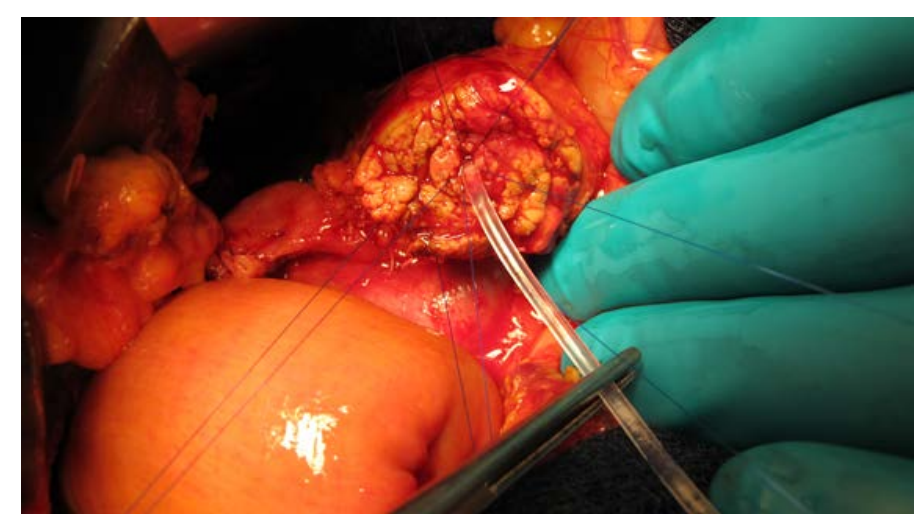

Figure 3. Anterior and posterior ductal sutures.

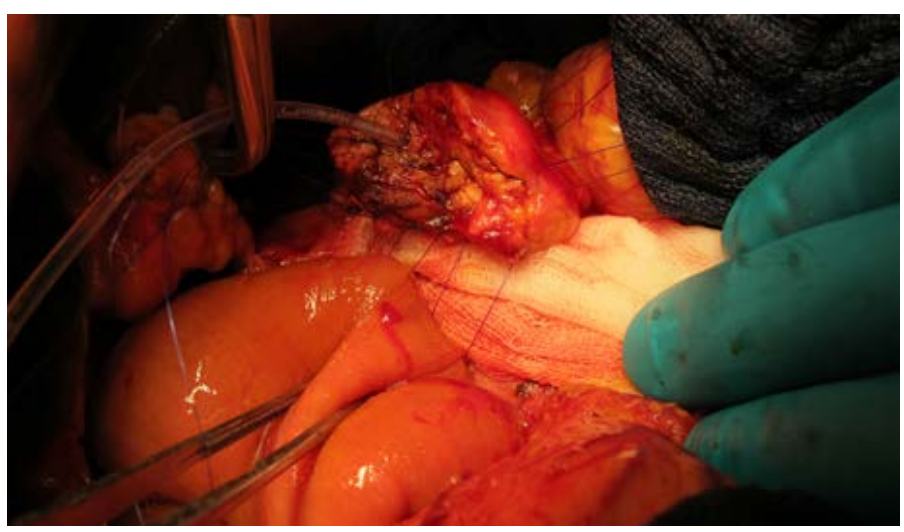

Figure 4. Posterior layer-horizontal mattress sutures. 


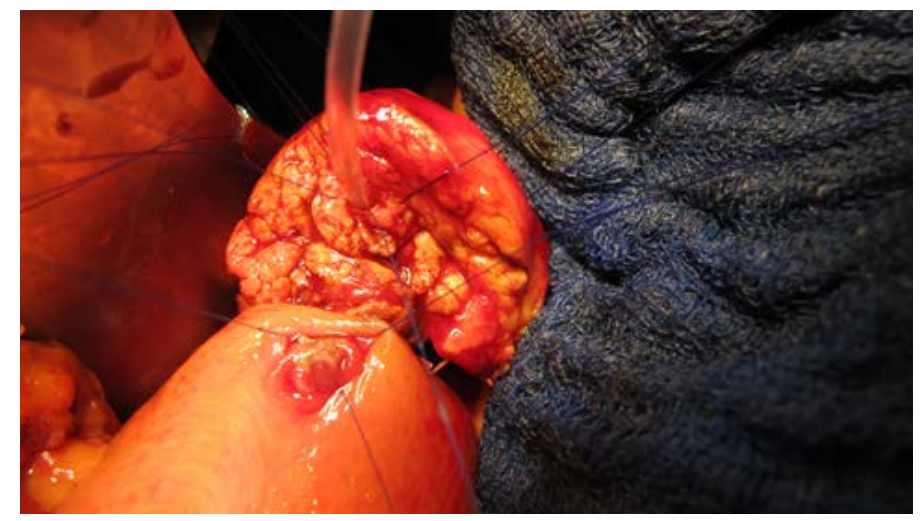

Figure 5. Posterior wall of the pancreatic duct is anastomosed to that of the opened jejunum.

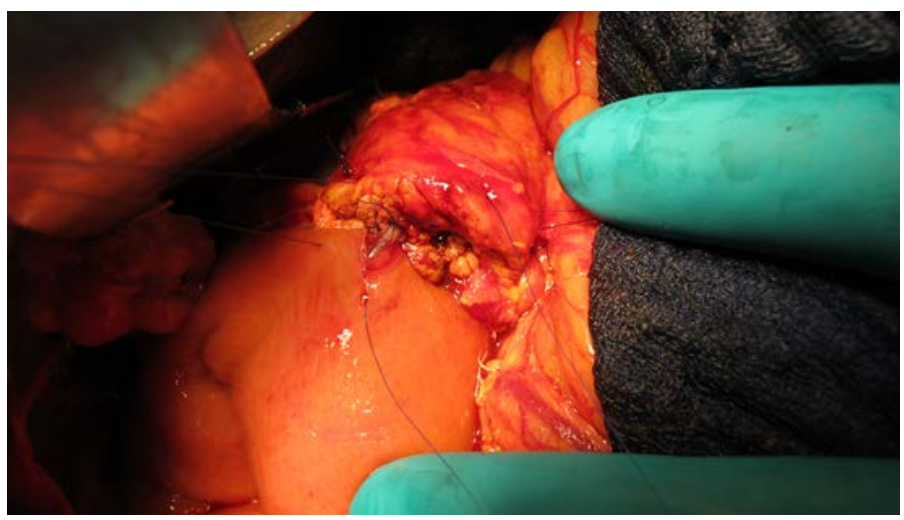

Figure 6. Anterior wall of the pancreatic duct is anteriorly anastomosed to the opened jejunum.

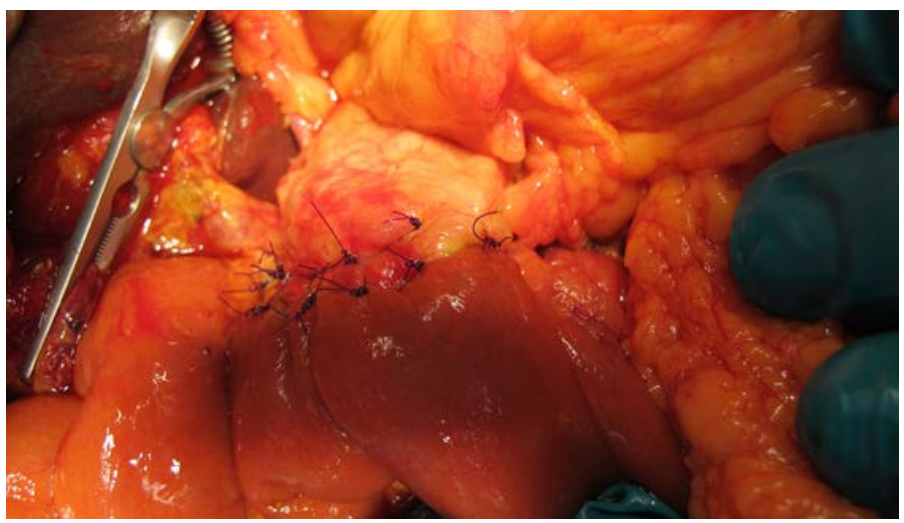

Figure 7. Anterior layer-interrupted sutures.

\section{Results}

Pancreatic leak was diagnosed in six patients (11.54\%), four males and two females at a mean age of 61 years (range: 45 - 72 years). Two patients were preoperatively scored to American Society of Anesthesiologists (ASA) as ASA I but four patients as ASA II. Three patients with PF of Grades A and B were managed conservatively, whereas three other patients with PF of Grade C required relaparotomy. The median time between the initial operation and relaparotomy was 7 days (range: 6 - 9 days). All the reoperations were performed as emergency procedures. Patients with Grade C PF were reoperated for abdominal sepsis and haemorrhage externalized 
through the abdominal drain $(n=3)$ and classified as Grade B $(n=1)$ or $C(n=2)$. In this series, the only cause of reoperation was PF with health-threatening complications. PF patients' reoperation rate was $50 \%$. Haemorrhage occurred in all the patients with Grade C PF. No haemorrhage occurred without PF. Patients with haemorrhage and peritonitis required hemostasis and completion pancreatectomy. Haemostasis was achieved by suture ligation. All the patients required intensive care unit treatment for life-threatening complications. One patient suffered single-organ dysfunction of Grade IVa and two patients suffered multi-organ dysfunction of Grade IVb. The mean operative blood loss was $820 \mathrm{~mL}$ (range: 100 - $2000 \mathrm{~mL}$ ). The mean transfusion of packed red blood cells required was 2.3 units (range: 0 - 6 units). Haemorrhage originated from erosion of the proper hepatic artery $(n=1)$, the stump of the gastroduodenal artery $(n=1)$ and from the cut surface of the pancreatic remnant $(n=1)$. The patient who required ligation of the proper hepatic artery for haemostasis secondary to hepatic artery erosion died of hepatic failure and refractory septic shock within three days postoperatively. PF patients' mortality rate was $16.67 \%$. Postoperative mortality rate of all the patients was $1.92 \%$. Eleven out of the rest 46 surgically treated patients $(23.91 \%)$ developed certain postoperative complication and suffered as a whole 20 such complications such as acute kidney failure (four), DGE (three), fistula of the biliodigestive anastomosis (one), pleural effusion (three), pneumonia (one), intrahepatic abscess (one), abdominal wall abscess (four), and postoperative diabetes mellitus requiring insulin therapy (three patients). Six complications were classified as Grade IIIa, one as Grade IIIb and nine as Grade II. Survivors' mean hospital stay length was 32 days (range: 24 - 50 days). All the patients required oral pancreatic enzyme replacement therapy.

\section{Discussion}

Common risk factors for pancreatic leakage are pancreatic texture including resection technique, MPD size, blood supply of the cut edge of the gland, patient's age, presence of jaundice, blood loss and, finally, anastomotic technique [20]. However, pancreatic texture, MPD size and anastomotic technique are the most significant factors [20]-[22]. This may be explained by three factors: 1) a soft parenchyma has a normal exocrine function and a high pancreatic juice output; 2 ) it is more likely associated with a small duct as an important factor for pancreatic leak, and 3) suturing it to the jejunal loop is associated with an increased risk of tangential lacerations of the pancreatic edge, which increase the risk of leaks from small pancreatic ducts, thus accounting for anastomotic failure.

The horizontal mattress sutures provide firmness that facilitates suture placement and avoids sutures cutting through. These sutures, possibly, close the small ducts within the gland and thus the correct tension on them is achieved to maintain a balance between reducing the risk of parenchymal tears and preventing the ischaemia of the pancreatic stump to the jejunum. The end-to-side PJ ensures that both jejunum and pancreas are lying in an anatomical position. This is crucial since an anastomosis of the pancreas, in particular an anastomosis of the digestive tract to a soft pancreatic parenchyma, is, probably, inherently unstable and even a slight tension can exert negative effects on its integrity. An end-to-side PJ is more anatomical in the sense that it can be better tailored according to the shape and texture of the pancreatic remnant. The PJ, possibly, requires less pancreatic remnant mobilization that is of importance for its blood supply. In our opinion, the number of sutures doesn't have any impact on the safety of the pancreatic anastomosis. That is why we make use of the single layer suture technique that represents a preventive measure against pancreatic leak. We use very fine sutures but employ as many as required without hesitation. The 5/0 and 4/0 PDS sutures with their fine needles ensure that the pancreatic capsule, pancreatic parenchyma, and the pancreatic duct are traumatized in the least while maintaining PJ integrity. This is especially important when the pancreatic texture is soft and friable and the duct is small in caliber. The application of MPD stent for smoothing the central parts, the anterior and posterior walls of presents with two advantages: 1) it enables a balanced suture tightening, with a decreased risk of tangential lacerations of the pancreatic edge and 2) the cut end of the pancreatic duct wall is "everted", and by this way, a wide MPD can be achieved. This is a simple procedure to avoid a compromise of the pancreatic ductal patency by "evaginating" MPD cut end. Furthermore, these fine sutures are less likely to cause MPD obstruction and hence pancreatic juice can flow freely into the jejunum. The internal pancreatic duct stenting and the "everted" pancreatic duct wall ensure that the opening jejunum and the pancretic duct are lying in an anatomical position. However, one randomized controlled trial shows that MPD drainage with a stent reduces the leakage rate of the pancreatic anastomosis after PD [23]. A meticulous duct to mucosa technique is more reliable in preventing the pancreatic leak and PF as compared to other techniques such as dunking of the pancreatic stump into the 
jejunum [24]. The application of our method achieves the effectiveness and sureness of the duct to mucosal technique, however, on the contrary, it is a single layer that makes it less traumatic and technically more feasible.

In the present study, the overall reoperation rate was $5.77 \%$ and the overall mortality rate was $1.92 \%$ which is in agreement with recent literature data available [25]-[30]. Mortality rate reduction in the centers across the world to less than $5 \%$ has prompted pancreatic surgeons to focus on these reduced rates that still remain between 30\% and 50\% [14] [31]-[33]. However, pancreatic anastomotic breakdown can lead to haemorrhage, peritonitis, sepsis and abscess development and requires reintervention in $10 \%-15 \%$ of the cases [22] and to a subsequent mortality increase after PD [34].

PFs remain problematic following elective PD despite advances in surgical technique and perioperative care. By definition, grade $\mathrm{C}$ fistula development may lead to death with a mortality rate of 39\% [35]. Recent large series from high-volume centres report overall mortality rates of $<2 \%$ following PD. So, grade C fistula is a significant contributor to death in many patients [36]. The safety of a pancreatico-digestive anastomosis is closely related to pancreatic remnant texture, which is the main determining factor of PF after PD [37]. The risk factors for the development of grade $\mathrm{C}$ fistulae are insufficiently studied yet. A soft pancreatic remnant, small duct size, excessive perioperative blood loss and pathology including ampullary, duodenal, cystic and islet cell neoplasms are most often associated with grade B and C PF [38]. Other authors report similar findings about any PFs without stratification to grades A, B or C [20]. Kawai et al. prove that a soft remnant and small duct size are significantly associated with grade B and C fistulae [39]. Such trends are not surprising given that these lesions, along with cystic and islet cell neoplasms, seldom lead to pancreatic duct obstruction or dilation and gland fibrosis, thereby resulting in a soft remnant for reconstruction. Gastroenteric leakage was established in 12 out of a total of 1036 patients (1.16\%) after PD. They underwent longer operative procedures and presented with a significantly longer, hospital stay, more PFs and other complications as well [40]. Among 471 consecutive patients, 57 (12.11\%) developed PFs after PD [41]. Grade A PF was found in 21 patients (4.46\%), Grade B PF-in 22 ones $(4.67 \%)$, and Grade C PF-in 14 ones $(2.97 \%)$. Soft pancreas $(\mathrm{p}=0.04)$, pancreatic duct located $<3 \mathrm{~mm}$ from the posterior border $(\mathrm{p}=0.02)$, cirrhotic liver $(\mathrm{p}=0.05)$, BMI $>25 \mathrm{~kg} / \mathrm{m}^{2}(\mathrm{p}=0.0001)$ and pancreatic duct diameter $<3 \mathrm{~mm}(\mathrm{p}<0.0001)$ were significantly associated with PF. Excessive intraoperative blood loss, obesity and a fatty pancreas are associated with a higher risk for PF development, too, although the relationships between these factors and grade C fistulae are less well-defined [39] [42] [43]. Most PFs can be managed non-operatively, but numerous grade C PFs don't require any reoperative intervention at all. Options include peripancreatic drainage with or without attempted repair of the site of leakage, construction of a new pancreaticenteric anastomosis, resection of the anastomosis with remnant ligation, and completion pancreatectomy.

\section{Conclusion}

This technique for PJ with a soft pancreas and non-dilated duct creates ideal conditions for anastomosis healing such as an excellent blood supply, an anatomical position with tension-free approximation and unobstructed pancreatic juice flow from the pancreas into the jejunal loop. According to our early experience with this modified technique for PJ, usage of horizontal mattress sutures, "everting" of MPD and its wall incorporation into a single layer pancreatic-enteric anastomosis are measures resulting in a low pancreatic anastomotic leakage rate after $\mathrm{PD}$.

\section{References}

[1] Buchler, M.W., Friess, H., Wagner, M., Kulli, C., Wagener, V. and Z’Graggen, K. (2000) Pancreatic Fistula after Pancreatic Head Resection. British Journal of Surgery, 87, 883-889. http://dx.doi.org/10.1046/j.1365-2168.2000.01465.x

[2] Makowiec, F., Riediger, H., Euringer, W., Uhl, M., Hopt, U.T. and Adam, U. (2005) Management of Delayed Visceral Arterial Bleeding after Pancreatic Head Resection. Journal of Gastrointestinal Surgery, 9, 1293-1299. http://dx.doi.org/10.1016/j.gassur.2005.08.003

[3] Choi, S.H., Moon, H.J., Heo, J.S., Joh, J.W. and Kim, Y.I. (2004) Delayed Hemorrhage after PancreaticoDuodenoctomy. Journal of the American College of Surgeons, 199, 186-191. http://dx.doi.org/10.1016/j.jamcollsurg.2004.04.005

[4] Shrikhande, S., Kleeff, J., Büchler, M. and Friess, H. (2007) Pancreatic Anastomosis after Pancreaticoduo Denectomy: How We Do It. Indian Journal of Surgery, 69, 224-229. http://dx.doi.org/10.1007/s12262-007-0031-3 
[5] Bassi, C., Falconi, M., Molinari, E., Mantovani, W., Butturini, G., Gumbs, A.A., et al. (2003) Duct-to-Mucosa versus End-to-Side Pancreaticojejunostomy Reconstruction after Pancreaticoduodenectomy: Results of a Prospective Randomized Trial. Surgery, 134, 766-771. http://dx.doi.org/10.1016/S0039-6060(03)00345-3

[6] Takano, S., Ito, Y., Watanabe, Y., Yokoyama, T., Kubota, N. and Iwai, S. (2000) Pancreaticojejunostomy versus Pancreatico-Gastrostomy in Reconstruction Following Pancreaticoduodenectomy. British Journal of Surgery, 87, 423427. http://dx.doi.org/10.1046/j.1365-2168.2000.01395.x

[7] Caronna, R., Peparini, N., Russillo, G., Rogano, A., Dinatale, G. and Chirletti, P. (2012) Pancreaticojejuno Anastomosis after Pancreaticoduodenectomy: Brief Pathophysiological Considerations for a Rational Surgical Choice. International Journal of Surgical Oncology, 2012, 1-4. http://dx.doi.org/10.1155/2012/636824

[8] Yang, S., Dou, K., Sharma, N. and Song, W. (2011) The Methods of Reconstruction of Pancreatic Digestive Continuity after Pancreaticoduodenectomy: A Meta-analysis of Randomized Controlled Trials. World Journal of Surgery, 35, 2290-2297. http://dx.doi.org/10.1007/s00268-011-1159-7

[9] Hayashibe, A. and Kameyama, M. (2008) Duct-to-Mucosa Pancreaticojejunostomies with a Hard Pancreas and Dilated Pancreatic Duct and Duct-to-Mucosa Pancreatico-Jejunostomies with a Soft Pancreas and Non-Dilated Duct. HPB (Oxford), 10, 54-57. http://dx.doi.org/10.1080/13651820701883130

[10] Cho, A., Yamamoto, H., Kainuma, O., Muto, Y., Park, S., Arimitsu, H., et al. (2014) Performing Simple and Safe Dunking Pancreaticojejunostomy Using Mattress Sutures in Pure Laparoscopic Pancreaticoduodenectomy. Surgical Endoscopy, 28, 315-318. http://dx.doi.org/10.1007/s00464-013-3156-4

[11] Hughes, S.J., Neichoy, B. and Behrns, K.E. (2014) Laparoscopic Intussuscepting Pancreaticojejunostomy. Journal of Gastrointestinal Surgery, 18, 208-212. http://dx.doi.org/10.1007/s11605-013-2308-0

[12] Chen, L. (2013) Applying Transductal Invaginational Pancreaticojejunostomy to Decrease Pancreatic Leakage after Pancreaticoduodenectomy. Hepatogastroenterology, 60, 1018-1020.

[13] Kakinoki, K., Okano, K., Oshima, M., Suto, H., Kashiwagi, H., Yamamoto, N., et al. (2014) A Novel Triple Secured Technique for Pancreatic Reconstruction Following Pancreaticoduodenectomy for a Soft Pancreas. Hepatogastroenterlogy, 61, 469-474.

[14] Bassi, C., Dervenis, C., Butturini, G., Fingerhut, A., Yeo, C., Izbicki, J., et al. (2005) Postoperative Pancreatic Fistula: An International Study Group (ISGPF) Definition. Surgery, 138, 8-13. http://dx.doi.org/10.1016/j.surg.2005.05.001

[15] Wente, M.N., Veit, J.A., Bassi, C., Dervenis, C., Fingerhut, A., Gouma, D.J., et al. (2007) Post-Pancreatectomy Haemorrhage (PPH): An International Study Group of Pancreatic Surgery (ISGPS) Definition. Surgery, 142, 20-25. http://dx.doi.org/10.1016/j.surg.2007.02.001

[16] Vincent, J.L. (2008) Clinical Sepsis and Septic Shock—Definition, Diagnosis and Management Principles. Langenbeck's Archives of Surgery, 393, 817-824. http://dx.doi.org/10.1007/s00423-008-0343-1

[17] Wente, M.N., Bassi, C., Dervenis, C., Fingerhut, A., Gouma, D.J., Izbicki, J.R., et al. (2007) Delayed Gastric Emptying (DGE) after Pancreatic Surgery: A Suggested Definition by the International Study Group of Pancreatic Surgery (ISGPS). Surgery, 142, 761-768. http://dx.doi.org/10.1016/j.surg.2007.05.005

[18] Dindo, D., Demartines, N. and Clavien, P.A. (2004) Classification of Surgical Complications: A New Proposal with Evaluation in a Cohort of 6336 Patients and Results of a Survey. Annals of Surgery, 240, 205-213. http://dx.doi.org/10.1097/01.sla.0000133083.54934.ae

[19] Reid-Lombardo, K.M., Farnell, M.B., Crippa, S., Barnett, M., Maupin, G., Bassi, C., et al., Pancreatic Anastomotic Leak Study Group (2007) Pancreatic Anastomotic Leakage after Pancreaticoduodenectomy in 1,507 Patients: A Report from the Pancreatic Anastomotic Leak Study Group. Journal of Gastrointestinal Surgery, 11, 1451-1458. http://dx.doi.org/10.1007/s11605-007-0270-4

[20] van Berg Henegouwen, M.I., de Wit, L.T., van Gulik, T.M., Obertop, H. and Gouma, D.J. (1997) Incidence, Risk Factors and Treatment of Pan Creatic Leakage after Pancreaticoduodenectomy: Drainage versus Resection of the Pancreatic Remnant. Journal of the American College of Surgeons, 185, 18-24. http://dx.doi.org/10.1016/S1072-7515(97)00007-0

[21] Yeo, C.J., Cameron, J.L., Lillemoe, K.D., Sauter, P.K., Coleman, J., Sohn, T.A., et al. (2000) Does Prophylactic Octreotide Decrease the Rates of Pancreatic Fistula and Other Complications after Pancreatico-Duodenectomy? Results of a Prospective Randomized Placebo-Controlled Trial. Annals of Surgery, 232, 419-429. http://dx.doi.org/10.1097/00000658-200009000-00014

[22] Munoz-Bongrand, N., Sauvanet, A., Denys, A., Sibert, A., Vilgrain, V. and Belghiti, J. (2004) Conservative Management of Pancreatic Fistula after Pancreatico-Duodenectomy with Pancreaticogastrostomy. Annals of Surgery, 199, 198-203. http://dx.doi.org/10.1016/j.jamcollsurg.2004.03.015

[23] Poon, R.T., Fan, S.T., Lo, C.M., Ng, K.K., Yuen, Y.K., Yeung, C. and Wong, J. (2007) External Drainage of Pancreatic Duct with a Stent to Reduce Leakage Rate of Pancreaticojejunostomy after Pancreaticoduodenectomy: A 
Prospective Randomized Trial. Annals of Surgery, 246, 425-433. http://dx.doi.org/10.1097/SLA.0b013e3181492c28

[24] Zhou, Y., Yang, C., Wang, S., Chen, J. and Li, B. (2011) Does External Pancreatic Duct Stent Decrease Pancreatic Fistula Rate after Pancreatic Resection? A Meta-Analysis. Pancreatology, 11, 362-370. http://dx.doi.org/10.1159/000330222

[25] Tien, Y.W., Lee, P.H., Yang, C.Y., Ho, M.C. and Chiu, Y.F. (2005) Risk Factors of Massive Bleeding Related to Pancreatic Leak after Pancreatico-Duodenectomy. Journal of the American College of Surgeons, 201, 554-559. http://dx.doi.org/10.1016/j.jamcollsurg.2005.05.007

[26] Shinchi, H., Takao, S., Maemura, K. and Aikou, T. (2006) A New Technique for Pancreaticogastrostomy for the Soft Pancreas: The Transfixing Suture Method. Journal of Hepato-Biliary-Pancreatic Surgery, 13, 212-217. http://dx.doi.org/10.1007/s00534-005-1036-6

[27] Nakahara, O., Takamori, H., Ikeda, O., Kuroki, H., Ikuta, Y., Chikamoto, A., Beppu, T., Yamashita, Y. and Baba, H. (2012) Risk Factors Associated with Delayed Haemorrhage after Pancreatic Resection. HPB (Oxford), 14, 684-687. http://dx.doi.org/10.1111/j.1477-2574.2012.00518.x

[28] Denbo, J., Orr, W., Zarzaur, B. and Behrman, S. (2012) Toward Defining Grade C Pancreatic Fistula Following Pancreaticoduodenectomy: Incidence, Risk Factors, Management and Outcome. HPB (Oxford), 14, 589-593. http://dx.doi.org/10.1111/j.1477-2574.2012.00486.X

[29] Aroori, S., Puneet, P., Bramhall, S., Muiesan, P., Mayer, A., Mirza, D., Buckels, J. and Isaac, J. (2011) Outcomes Comparing a Pancreaticogastrostomy (PG) and a Pancreaticojejunostomy (PJ) after a Pancreatico-Duodenectomy (PD). HPB (Oxford), 13, 723-731. http://dx.doi.org/10.1111/j.1477-2574.2011.00363.x

[30] Denost, Q., Pontallier, A., Rault, A., Ewald, J., Collet, D., Masson, B. and Sa-Cunha, A. (2012) Wirsungostomy as a Salvage Procedure after Pancreaticoduodenectomy. HPB (Oxford), 14, 82-86. http://dx.doi.org/10.1111/j.1477-2574.2011.00406.x

[31] Shukla, P.J. and Barreto, S.G. (2008) Improving the Safety and Outcome of Uncinate Process Dissection in Surgery on the Pancreatic Head. HPB (Oxford), 10, 214. http://dx.doi.org/10.1080/13651820802029443

[32] Diener, M.K., Rahbari, N.N., Fischer, L., Antes, G., Büchler, M.W. and Seiler, C.M. (2008) Duodenum-Preserving Pancreatic Head Resection versus Pancreatoduodenectomy for Surgical Treatment of Chronic Pancreatitis. A Systematic Review and Meta-Analysis. Annals of Surgery, 247, 950-961. http://dx.doi.org/10.1097/SLA.0b013e3181724ee7

[33] Shrikhande, S.V., Barreto, G. and Shukla, P.J. (2008) Pancreatic Fistula after Pancreaticoduodenectomy: The Impact of a Standardized Technique of Pancreatico-Jejunostomy. Langenbecks Archives of Surgery, 393, 87-91. http://dx.doi.org/10.1007/s00423-007-0221-2

[34] Blanc, T., Cortes, A., Goere, D., Sibert, A., Pessaux, P., Belghiti, J. and Sauvanet, A. (2007) Haemorrhage after Pancreaticoduodenectomy: When Is Surgery Still Indicated? American of Surgery, 194, 3-9. http://dx.doi.org/10.1016/j.amjsurg.2006.08.088

[35] Denbo, J.W., Orr, W.S., Zarzaur, B.L. and Behrman, S.W. (2012) Toward Defining Grade C Pancreatic Fistula Following Pancreaticoduodenectomy: Incidence, Risk Factors, Management and Outcome. HPB (Oxford), 14, 589-593. http://dx.doi.org/10.1111/j.1477-2574.2012.00486.x

[36] Veillette, G., Dominguez, I., Ferrone, C., Thayer, S.P., McGrath, D., Warshaw, A.L., et al. (2008) Implications and Management of Pancreatic Fistulas Following Pancreaticoduodenectomy. Archives of Surgery, 143, 476-481. http://dx.doi.org/10.1001/archsurg.143.5.476

[37] Denost, Q., Pontallier, A., Rault, A., Ewald, J.A., Collet, D., Masson, B. and Sa-Cunha, A. (2012) Wirsungostomy as a Salvage Procedure after Pancreaticoduodenectomy. HPB (Oxford), 14, 82-86.

[38] Fuks, D., Piessen, G., Huet, E., Tavernier, M., Zerbib, P., Michot, F., et al. (2009) Life-Threatening Postoperative Pancreatic Fistula (Grade C) after Pancreatico-Duodenectomy: Incidence, Prognosis and Risk Factors. American of Surgery, 197, 702-709. http://dx.doi.org/10.1016/j.amjsurg.2008.03.004

[39] Kawai, M., Kondo, S., Yamaue, H., Wada, K., Sano, K., Motoi, F., et al. (2011) Predictive Risk Factors for Clinically Relevant Pncreatic Fistula Analysed in 1239 Patients with Pancreaticoduodenectomy: Multicentre Data Collection as a Project Study of Pancreatic Surgery by the Japanese Society of Hepato-Biliary-Pancreatic Surgery. Journal of Hepato-Biliary-Pancreatic Sciences, 18, 601-608. http://dx.doi.org/10.1007/s00534-011-0373-X

[40] Eshuis, W.J., Tol, J.A., Nio, C.Y., Busch, O.R., van Gulik, T.M. and Gouma, D.J. (2014) Leakage of the Gastroenteric Anastomosis after Pancreato-Duodenectomy. Surgery, 156, 75-82. http://dx.doi.org/10.1016/j.surg.2014.03.044

[41] El Nakeeb, A., Salah, T., Sultan, A., El Hemaly, M., Askr, W., Ezzat, H., et al. (2013) Pancreatic Anastomotic Leakage after Pancreatico-Duodenectomy. Risk Factors, Clinical Predictors and Management (Single Center Experience). World Journal of Surgery, 37, 1405-1418. http://dx.doi.org/10.1007/s00268-013-1998-5 
[42] Gaujoux, S., Cortes, A., Couvelard, A., Noullet, S., Clavel, L., Rebours, V., Lévy, P., Sauvanet, A., Ruszniewski, P. and Belghiti, J. (2010) Fatty Pancreas and Increased Body Mass Index Are Risk Factors of Pancreatic Fistula after Pancreaticoduodenectomy. Surgery, 148, 39-47. http://dx.doi.org/10.1016/j.surg.2009.12.002

[43] Tsai, S., Choti, M.A., Assumpcao, L., Cameron, J.L., Gleisner, S.L., Herman, J.M., Eckhauser, F., Edil, B.H., Schulick, R.D., Wolfgang, C.L. and Pawlik, T.M. (2010) Impact of Obesity on Perioperative Outcomes and Survival Following Pancreaticoduodenectomy for Pancreatic Cancer: A Large Single-Institution Study. Journal of Gastrointestinal Surgery, 14, 1143-1150. http://dx.doi.org/10.1007/s11605-010-1201-3 
Scientific Research Publishing (SCIRP) is one of the largest Open Access journal publishers. It is currently publishing more than 200 open access, online, peer-reviewed journals covering a wide range of academic disciplines. SCIRP serves the worldwide academic communities and contributes to the progress and application of science with its publication.

Other selected journals from SCIRP are listed as below. Submit your manuscript to us via either submit@scirp.org or Online Submission Portal.
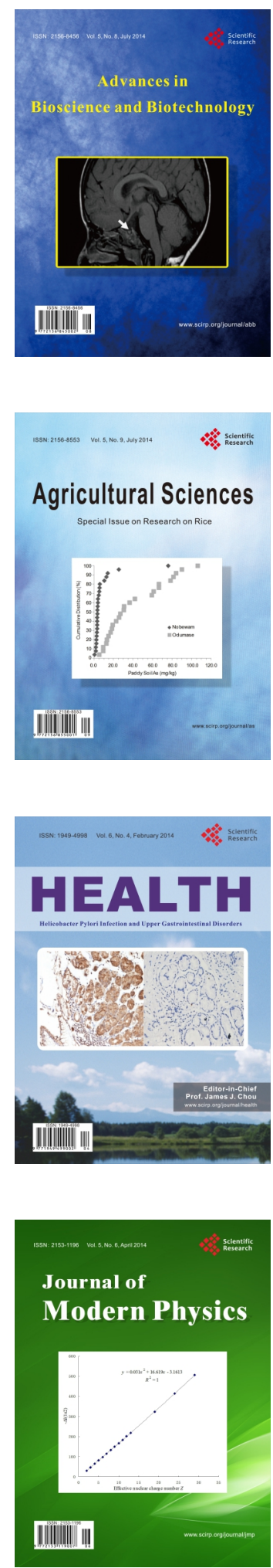
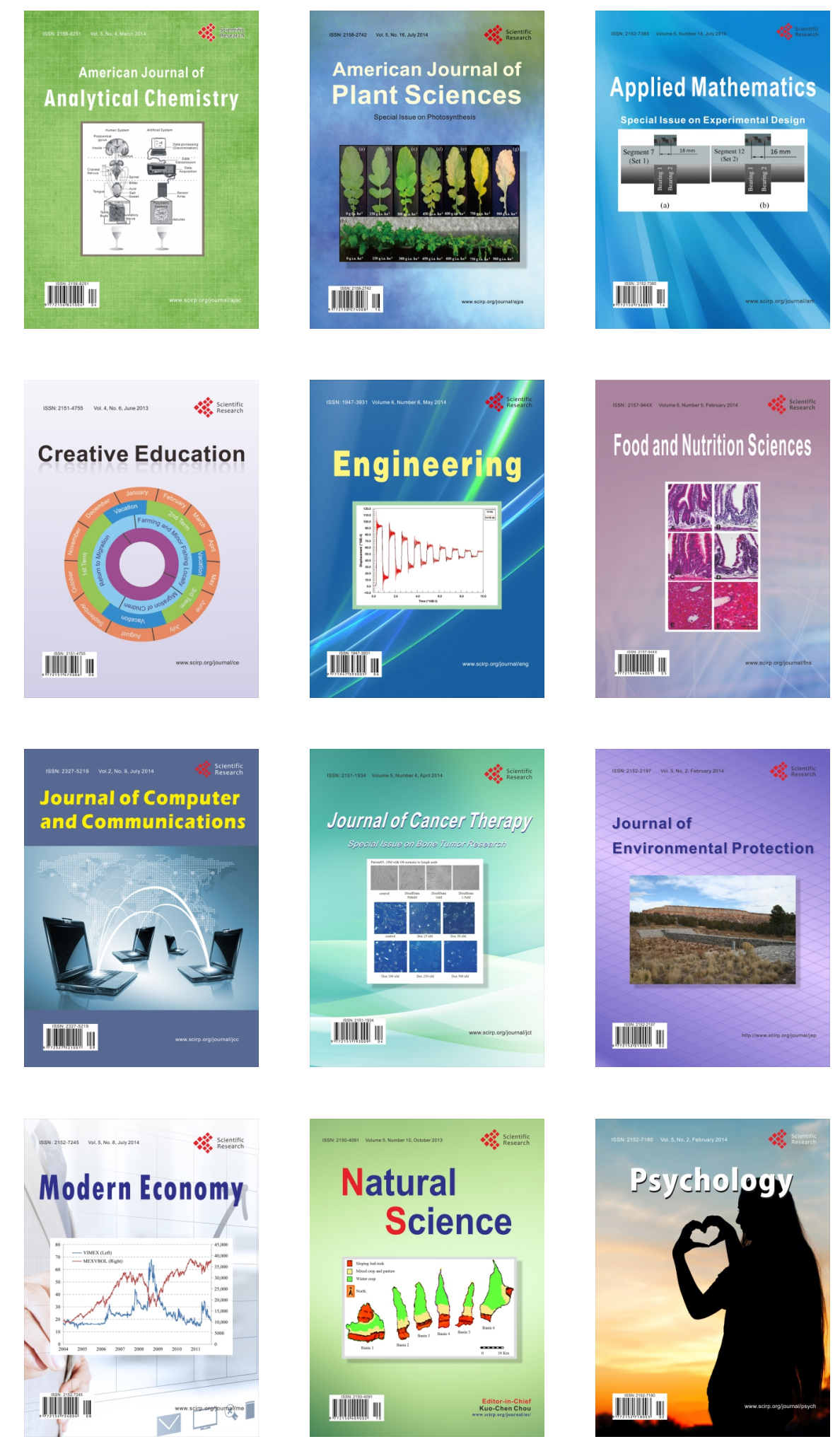